\title{
Diagnostic ability of linked color imaging in ultraslim endoscopy to identify neoplastic lesions in the upper gastrointestinal tract
}

\section{(ㄷ)(우우}

\section{Authors}

Ken Haruma ${ }^{1}$, Mototsugu Kato ${ }^{2}$, Kenro Kawada ${ }^{3}$, Takahisa Murao ${ }^{4}$, Shoko Ono ${ }^{5}$, Mitsuhiko Suehiro ${ }^{1}$, Shinichiro Hori' Fumisato Sasaki ${ }^{7}$, Tomoyuki Koike ${ }^{8}$, Shinji Kitamura ${ }^{9}$, Osamu Dohi ${ }^{10}$, Hiromitsu Kanzaki ${ }^{11}$, Nobuaki Yagi ${ }^{12}$, Keiichi Hashiguchi ${ }^{13}$, Shiro Oka ${ }^{14}$, Kazuhiro Katada ${ }^{15}$, Ryo Shimoda ${ }^{16}$, Kazuhiro Mizukami ${ }^{17}$, Toshihisa Takeuchi ${ }^{18}$, Shinichi Katsuki ${ }^{19}$, Momoko Tsuda ${ }^{5}$, Yuji Naito ${ }^{10}$, Tatsuyuki Kawano ${ }^{20}$, Keita Mori' ${ }^{21}$, Hideki Ishikawa ${ }^{22}$

Institutions

1 Department of General Internal Medicine 2, Kawasaki Medical School General Medical Center, Okayama, Japan

2 Department of Gastroenterology, National Hospital Organization Hakodate National Hospital, Hokkaido, Japan

3 Department of Gastrointestinal Surgery, Tokyo Medical and Dental University, Tokyo, Japan

4 Division of Gastroenterology Department of Internal Medicine, Kawasaki Medical School, Okayama, Japan

5 Division of Endoscopy, Hokkaido University Hospital, Hokkaido, Japan

6 Department of Endoscopy, National Hospital Organization Shikoku Cancer Center, Ehime, Japan

7 Digestive and Lifestyle Diseases, Kagoshima University Graduate School of Medical and Dental Sciences, Kagoshima, Japan

8 Division of Gastroenterology, Tohoku University Graduate School of Medicine, Sendai, Japan

9 Department of Gastroenterology and Oncology, Tokushima University Graduate School of Biomedical Sciences, Tokushima, Japan

10 Department of Molecular Gastroenterology and Hepatology, Graduate School of Medical Science, Kyoto Prefectural University of Medicine, Kyoto, Japan

11 Department of Gastroenterology and Hepatology, Okayama University Graduate School of Medicine, Dentistry, and Pharmaceutical Sciences, Okayama, Japan

12 Department of Gastroenterology, Asahi University Hospital, Gifu, Japan

13 Department of Endoscopy, Nagasaki University Hospital, Nagasaki, Japan

14 Department of Endoscopy, Hiroshima University Hospital, Hiroshima, Japan

15 Department of Gastroenterology and Hepatology, North Medical Center, Kyoto Prefectural University of Medicine, Kyoto, Japan
16 Internal Medicine and Gastrointestinal Endoscopy, Saga University, Saga, Japan

17 Department of Gastroenterology, Oita University, Oita, Japan

18 Second Department of Internal Medicine, Osaka Medical College, Osaka, Japan

19 Gastroenterology, Otaru Ekisaikai Hospital, Hokkaido, Japan

20 Department of Surgery, Soka Municipal Hospital, Saitama, Japan

21 Clinical Research Promotion Unit, Clinical Research Center, Shizuoka Cancer Center, Shizuoka, Japan

22 Department of Molecular-Targeting Cancer Prevention, Kyoto Prefectural University of Medicine, Osaka, Japan

submitted 3.5.2021

accepted after revision 12.10 .2021

Bibliography

Endosc Int Open 2022; 10: E88-E95

DOI 10.1055/a-1723-2635

ISSN 2364-3722

(c) 2022. The Author(s).

This is an open access article published by Thieme under the terms of the Creative Commons Attribution-NonDerivative-NonCommercial License, permitting copying and reproduction so long as the original work is given appropriate credit. Contents may not be used for commercial purposes, or adapted, remixed, transformed or built upon. (https://creativecommons.org/licenses/by-nc-nd/4.0/)

Georg Thieme Verlag KG, Rüdigerstraße 14,

70469 Stuttgart, Germany

Corresponding author

Ken Haruma MD, PhD, Department of General Internal Medicine 2, Kawasaki Medical School General Medical Center, 2-6-1, Nakasange, Kita-ku, Okayama 700-8505, Japan Fax: +81-86-462-1199

kharuma@med.kawasaki-m.ac.jp 


\section{ABSTRACT}

Background and study aims Linked color imaging $(\mathrm{LCl})$ is a new image-enhancing technique that facilitates the differentiation of slight differences in mucosal color tone. We performed an exploratory analysis to evaluate the diagnostic capability of $\mathrm{LCl}$ in ultraslim endoscopy, using data from patients examined in the LCI-Further Improving Neoplasm Detection in upper gastrointestinal (LCI-FIND) trial, a largescale, multicenter, randomized controlled trial that demonstrated the capability of LCI for detecting neoplastic lesions in the upper gastrointestinal tract.

Patients and methods Data from the LCI-FIND prospective trial were used. In the LCI-FIND trial, 1502 patients with a history of gastrointestinal cancer were randomly assigned to two groups based on examination methods: white light imaging (WLI) followed by LCI (WLI group) and
LCI followed by WLI (LCI group). The present exploratory analysis investigated the outcomes of patients who underwent ultraslim and standard endoscopies.

Results Ultraslim endoscopes were used in 223 patients and standard endoscopes in 1279 patients. The primary endpoint of the LCI-FIND trial was the percentage of patients diagnosed with a neoplastic lesion using WLI or LCI. The corresponding percentage tended to be higher with $\mathrm{LCI}$ than with WLI among patients who underwent ultraslim endoscopy and among those who underwent standard endoscopy; the crude risk ratio was 2.21 [95\% confidence interval $(\mathrm{Cl})$ : 1.06-4.67], and the adjusted odds ratio was 2.46 (95\% Cl: 1.07-5.63).

Conclusions Our exploratory analysis of data from the LCIFIND trial showed that $\mathrm{LCl}$ is useful in identifying neoplastic lesions, when used in ultraslim endoscopy.

\section{Introduction}

Upper gastrointestinal endoscopy mainly detects neoplastic lesions in the pharynx, esophagus, and stomach. However, conventional white light imaging (WLI) is disadvantageous because it is likely to overlook early-stage lesions [1-3]. A new image processing technique, linked color imaging ( $\mathrm{LCl}$ ), was developed for the LASEREO system using laser beams (Fujifilm Corporation, Tokyo, Japan). $\mathrm{LCl}$ is an image-enhanced endoscopic observation method in which conventional white light and short-wavelength narrowband light are applied simultaneously in an appropriately balanced manner to emphasize slight color differences of the membrane by making reddish colors appear redder and whitish colors whiter through simultaneous enhancement and weakening of colors. Although the usefulness of $\mathrm{LCl}$ in the qualitative diagnosis of upper gastrointestinal lesions has been reported [4-14]. There has been no large-scale clinical trial focused on detection and diagnosis of upper gastrointestinal lesions. We previously conducted a large-scale randomized controlled clinical trial-the LCI-Further Improving Neoplasm Detection in upper gastrointestinal (LCI-FIND) trialand demonstrated the capability of $\mathrm{LCI}$ for detecting neoplastic lesions in the upper gastrointestinal tract [15].

Endoscopes used for observation of the upper gastrointestinal tract are divided into two types: ultraslim and standard with a relatively larger caliber. Whereas standard endoscopes can only be inserted transorally, ultraslim endoscopes can be inserted transorally and transnasally, causing less burden on the patient undergoing endoscopic examination. However, because of the small caliber, ultraslim endoscopy has a risk of producing lower-quality images and decreased operability compared with standard endoscopy. There is, however, a recent report documenting that ultraslim endoscopy is equivalent to standard endoscopy in terms of diagnostic capability.[16] The LCI-FIND trial used both ultraslim and standard endoscopic instruments. Hence, we performed a sub-analysis using data from the $\mathrm{LCl}$ FIND trial to examine whether the ability of ultraslim endoscopy to detect neoplastic lesions is no-inferior to that of standard endoscopy.

\section{Patients and methods}

Since the methods used in the LCI-FIND trial have been described in detail in a previous report on the results of the primary endpoint [15], only an outline of the methods is shown here.

\section{Patients}

The subjects were patients aged 20 to 89 years who were scheduled for upper gastrointestinal endoscopy in 19 major hospitals in Japan. All of them were known to have a history or current diagnosis of gastrointestinal cancer (pharyngeal, esophageal, gastric, or colorectal).

This study was performed after obtaining approval from the institutional review boards of all participating institutions. This study is registered under the UMIN Clinical Trial Registry (UMIN000023863). Written informed consent was obtained from all subjects. This study received the provision of medical equipment and financial support from Fujifilm Corporation, but an agreement was made that the company would not influence the content and results of the study.

\section{Methods}

This study was conducted after patient recruitment as a posthoc analysis of the LCl study. The minimization method was used for the random assignment of the patients. The following four stratification factors were used: facility, age $(\geq 70$ or $<70$ years), presence/absence of current cancer, and presence/absence of surgical history of gastric or esophageal resection.

The endoscopic devices used included LASEREO, LASEREO 7000 system, and upper gastrointestinal endoscopes (EGL580NW, EG-L590WR, EG-L590ZW, EG-L600ZW, EGL580NW7, EG-L600WR7, and EG-L600ZW7) (Fujifilm Corporation, Tokyo, Japan). The choice of endoscopic equipment was 
left to the free will of the endoscopists. In this study, patients in whom EG-L580NW or EG-L580NW7 were used were in the group subjected to ultraslim endoscopy, and those in whom other endoscopes with greater calibers were used were in the group subjected to standard endoscopy.

The image resolution of endoscopy was evaluated by the United States Air Force (USAF) resolution test chart (> Fig. 1) on a monitor of the endoscopy system at distances of $50 \mathrm{~mm}$ and $70 \mathrm{~mm}$ between the distal end of the endoscopy and the chart. Evaluated endoscopes were EG-L580NW7 categorized as ultraslim-scope, EG-L590WR and EG-L600WR7 as standardscope. EG-L580NW used in this study has the same optical specification as L580NW7. Also, EG-L590ZW was the same as EGL590WR and EG-L600ZW7 were the same as EG-600WR7 in optical specification, respectively. Image resolution was defined by the maximal resolvable lines per $\mathrm{mm}$ of the USAF test chart. The results are shown in $>$ Table 1. The EG-L580NW7 and EGL590WR had almost the same resolution and the EG-L600WR7 had higher resolution than two scopes.

During the endoscopic procedure, each location was observed with WLI followed by $\mathrm{LCl}$ (WLI group) or with $\mathrm{LCl}$ followed by WLI (LCI group). The number of detected lesions, neoplastic/nonneoplastic, and the degree of endoscopist's confidence (high/low) about the malignant potential were recorded for each observation of each location. The degree of endoscopist confidence was rated as high when the endoscopist judged the lesion as being definitely cancer, whereas it was rated as low when the endoscopist judged that the possibility of cancer was not deniable for the lesion. The time required for observation of the esophagus and stomach was calculated from the recorded time data on photographs taken at the beginning and end of the observation of each location.

Biopsy specimens were obtained from all diagnosed lesions. Neoplastic lesions were defined as high-grade dysplasia and carcinoma of the pharynx, intraepithelial neoplasia (IN), carcinomas of the esophagus, and adenoma and carcinoma of the stomach. Duodenal lesions were not included in this study because of their low frequency.

Endpoints included the percentage of patients diagnosed with pharyngeal, esophageal, or gastric neoplastic lesions observed by $\mathrm{WLI}$ and $\mathrm{LCl}$ in the primary mode; the percentages of patients diagnosed with a neoplastic lesion observed by WLI and $\mathrm{LCl}$ in the primary mode by location, size, morphology type, and degree of endoscopist confidence; and neoplastic lesions detected by $\mathrm{WLI}$ and $\mathrm{LCl}$ in the secondary mode.

The presence of Helicobacter pylori infection was not assessed in this study.

\section{Statistical analysis}

Patients who underwent standard endoscopy and those who underwent ultraslim endoscopy were analyzed separately. Since this was an exploratory study that used data after the confirmatory analysis of the primary endpoint, the percentage and $95 \%$ confidence interval $(\mathrm{Cl})$ were calculated and presented for each item. The $95 \% \mathrm{Cl}$ was calculated by exact binomial distribution. As for relative risk, the crude risk ratio without adjustment, odds ratio adjusted for age, presence/absence of cur-

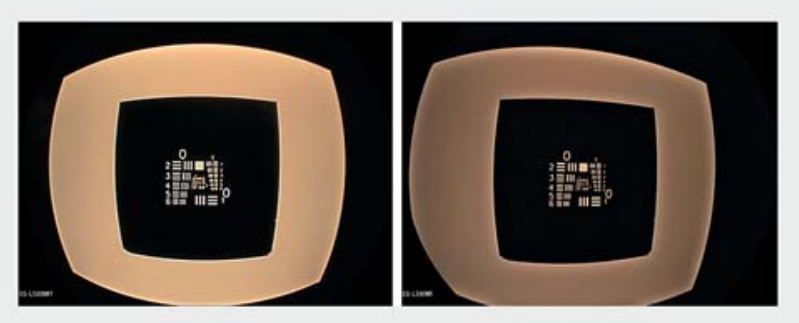

- Fig. 1 The images shown are a comparison of resolution chart at a $50-\mathrm{mm}$ distance between the scope and the resolution chart. The distinguishable lines are 1 to 2 for the ultraslim endoscopy (left) and 1 to 3 for the normal-diameter endoscopy (right), which when converted to resolution are $2.24 \mathrm{LP} / \mathrm{mm}$ and $2.52 \mathrm{LP} / \mathrm{mm}$, respectively.

- Table 1 Results of image resolution evaluation on the ultraslimscope and the standard scopes using the USAF test chart.

\begin{tabular}{|l|l|l|}
\hline Endoscope & \multicolumn{2}{|l|}{ Resolution (lines/mm) } \\
\hline & $\mathbf{5 0 ~} \mathbf{~ m}$ & $\mathbf{7 0 ~} \mathbf{~ m}$ \\
\hline EG-L580NW7 & 2.24 & 1.41 \\
\hline EG-L590WR & 2.52 & 1.59 \\
\hline EG-L600WR7 & 3.56 & 2.52 \\
\hline USAF, United States Air Force. & & \\
\hline
\end{tabular}

rent cancer, and presence/absence of surgical history using a logistic model, and $95 \% \mathrm{Cl}$ were calculated.

\section{Results}

A total of 1,508 patients were recruited between November 2016 and July 2018, and 1,504 patients who gave consent to the study were registered and randomized to the WLI (753 patients) and the LCl groups (752 patients). The final population for evaluation comprised 751 patients in the WLI group and 750 patients in the $\mathrm{LCl}$ group, excluding two patients: one patient in the WLI group who underwent standard endoscopy because of a large amount of residue and another patient in the $\mathrm{LCl}$ group who underwent standard endoscopy because of stenosis caused by pharyngeal neoplasm ( $>$ Fig. 2 ).

Ultraslim endoscopes were used in 223 patients, and standard endoscopes were used in 1,279 patients. Standard endoscopes were inserted transorally in all the 1,279 patients, whereas ultraslim endoscopes were inserted transorally in 44 $(19.7 \%)$ patients and transnasally in the remaining patients. The number of examinations for each type of endoscopy by medical facility are shown in > Table 2.

Baseline characteristics of the study subjects are shown in - Table 3. Among the patients who underwent ultraslim endoscopy, the presence of current cancer was slightly more frequent in the LCl group, and the history of radiation therapy was slightly more frequent in the WLI group. Sedation was performed in 28 of 223 patients (12.6\%) in the ultraslim group and 502 of 
Recruited: 1508

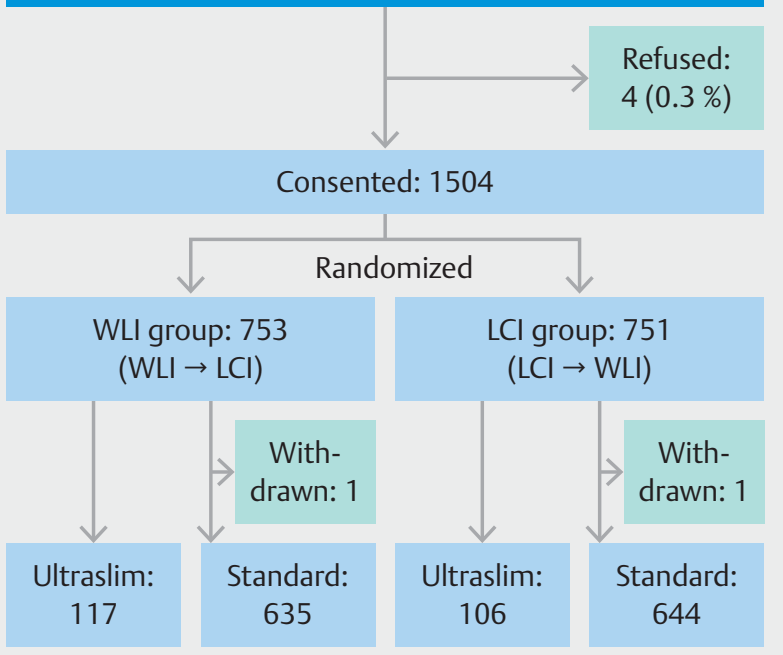

Fig. 2 Consort diagram.

1279 patients (39.2\%) in the standard group, with a significantly higher rate in the standard group $(P<0.001)$.

Neoplastic lesions were detected in 48 of 530 patients (9.06\%) in the sedation group and 77 of 972 patients (7.92\%) in the non-sedation group, with a slight but not significant difference in the sedation group $(P=0.447)$.

- Fig. 3 shows the $\mathrm{LCl}$ and WLI endoscopic images of representative cancer lesions in the esophagus obtained by ultraslim endoscopy.

- Table 4 shows the numbers of neoplastic lesions and patients with neoplastic lesions detected by ultraslim endoscopy or standard endoscopy with WLI and $\mathrm{LCl}$ in the primary and secondary modes. The primary endpoint of the LCI-FIND trial was the percentage of patients diagnosed with a neoplastic lesion using WLI or LCl in the primary mode. Among patients who underwent ultraslim endoscopy, the corresponding percentage in
Table 2 Number of examinations for each type of endoscope by medical facility.

\begin{tabular}{|c|c|c|c|}
\hline Facility & $\begin{array}{l}\text { Ultraslim } \\
\text { endoscope }\end{array}$ & $\begin{array}{l}\text { Standard } \\
\text { endoscope }\end{array}$ & Total \\
\hline A & 21 & 471 & 492 \\
\hline B & 0 & 344 & 344 \\
\hline C & 145 & 1 & 146 \\
\hline D & 1 & 90 & 91 \\
\hline $\mathrm{E}$ & 1 & 71 & 72 \\
\hline $\mathrm{F}$ & 3 & 68 & 71 \\
\hline G & 0 & 57 & 57 \\
\hline $\mathrm{H}$ & 43 & 11 & 54 \\
\hline I & 0 & 44 & 44 \\
\hline J & 2 & 29 & 31 \\
\hline K & 1 & 20 & 21 \\
\hline L & 0 & 21 & 21 \\
\hline$M$ & 0 & 16 & 16 \\
\hline$N$ & 0 & 13 & 13 \\
\hline O & 0 & 10 & 10 \\
\hline$P$ & 0 & 8 & 8 \\
\hline Q & 6 & 0 & 6 \\
\hline $\mathrm{R}$ & 0 & 4 & 4 \\
\hline$S$ & 0 & 1 & 1 \\
\hline Total & 223 & 1279 & 1502 \\
\hline
\end{tabular}

primary mode was significantly higher in $\mathrm{LCl}$ than in WLI group; the crude risk ratio was 2.21 (95\% Cl: 1.06-4.67), and the adjusted odds ratio was 2.46 (95\% Cl: 1.07-5.63). In secondary mode, the percentage of patients diagnosed with a neoplastic lesion tended to be lower in $\mathrm{LCl}$; the crude risk ratio was 0.28

- Table 3 Baseline characteristics of the study subjects.

\begin{tabular}{|c|c|c|c|c|}
\hline & \multicolumn{2}{|c|}{ Ultraslim endoscopy ( $N=223$ ) } & \multicolumn{2}{|c|}{ Standard endoscopy $(N=1279)$} \\
\hline & $\begin{array}{l}\text { WLI group } \\
(N=117)\end{array}$ & $\begin{array}{l}\text { LCl group } \\
(N=106)\end{array}$ & $\begin{array}{l}\text { WLI group } \\
(N=635)\end{array}$ & $\begin{array}{l}\mathrm{LCl} \text { group } \\
(\mathrm{N}=644)\end{array}$ \\
\hline Age & $73(66-77)$ & $71(67-76)$ & $71(66-77)$ & $72(66-77)$ \\
\hline Age $<70$ years & $44(37.6 ; 28.8-47.0)$ & $40(37.7 ; 28.5-47.7)$ & $255(40.2 ; 36.3-44.1)$ & $259(40.2 ; 36.4-44.1)$ \\
\hline Male & $95(81.2 ; 72.9-87.8)$ & $86(81.1 ; 72.4-88.1)$ & $483(76.1 ; 72.6-79.3)$ & $496(77.0 ; 73.6-80.2)$ \\
\hline Surgical history & $16(13.7 ; 8.0-21.3)$ & $13(12.3 ; 6.7-20.1)$ & $62(9.8 ; 7.6-12.3)$ & $72(11.2 ; 8.9-13.9)$ \\
\hline Current cancer & $16(13.7 ; 8.0-21.3)$ & $19(17.9 ; 11.2-26.6)$ & $103(16.2 ; 13.4-19.3)$ & $102(15.8 ; 13.1-18.9)$ \\
\hline History of radiation therapy & $32(27.4 ; 19.5-36.4)$ & $24(22.6 ; 15.1-31.8)$ & $56(8.8 ; 6.7-11.3)$ & $63(9.8 ; 7.6-12.3)$ \\
\hline
\end{tabular}




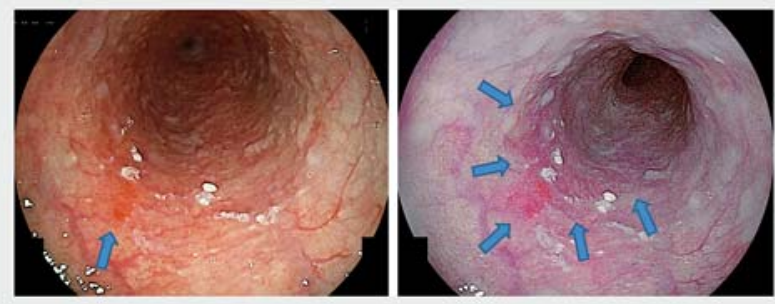

- Fig. 3 Typical case of early esophageal cancer detected by ultraslim endoscopy with linked color imaging. The white light imaging image on the left shows only a slight reddening of the arrowhead area, whereas the linked color imaging on the right shows a welldefined, reddish depression, which is recognizable as a depressed early-stage esophageal cancer

(95\% Cl: 0.04-2.45), and the adjusted odds ratio was 0.27 (95\% $\mathrm{Cl}$ : 0.04-1.83). In contrast, among patients who underwent standard endoscopy, the percentage of patients diagnosed with a neoplastic lesion in primary mode was higher in $\mathrm{LCl}$ than in WLI; the crude risk ratio was 1.53 (95\% Cl: $0.96-2.45)$, and the adjusted odds ratio was 1.57 (95\% Cl: $0.96-2.57$ ), while the corresponding percentage in secondary mode was significantly lower in the $\mathrm{LCl}$ group; the crude risk ratio was 0.18 (95\% Cl: $0.07-0.49$ ), and the adjusted odds ratio was 0.17 (95\% Cl: $0.06-0.49)$.
- Table 5 shows the number of neoplastic lesions detected in the primary mode according to location, size, and morphological type of the lesion. Among patients who underwent ultraslim endoscopy, the number of neoplastic lesions detected by $\mathrm{LCl}$ was greater than that detected by WLI in all cases, except for pharyngeal lesions and lesions measuring 11-20 mm, in which the number of lesions detected by WLI and LCI were comparable and diffuse lesions in which the number of detected lesions by LCI was one-third of that detected by WLI. In particular, the ability of $\mathrm{LCl}$ to detect esophageal lesions and depressed lesions was suggested to be higher in ultraslim endoscopy than in standard endoscopy.

- Table 6 shows the number of lesions biopsied for suspicion of tumor and the number of detected tumors by location. Among patients examined by ultraslim endoscopy, the proportion of detected tumors to all biopsied lesions was higher for $\mathrm{LCl}$ than for WLI. The superiority of $\mathrm{LCl}$ was more prominent in these patients than in those examined by standard endoscopy.

\section{Discussion}

The previously reported LCI-FIND trial [15] demonstrated that $\mathrm{LCl}$ detected neoplastic lesions significantly better, by 1.67 times, than WLI. In this regard, the superiority of LCI to WLI in the diagnostic ability when used in ultraslim endoscopy was examined in this study. The results showed that the potential of ultraslim endoscopy with $\mathrm{LCl}$ was comparable to that of standard endoscopy with LCI. In particular, the results suggested that

- Table4 Patient-based results (primary results): neoplastic lesions detected using WLI and LCI in primary and secondary modes.

\begin{tabular}{|c|c|c|c|c|c|c|c|c|c|}
\hline & & \multicolumn{4}{|c|}{ Ultraslim endoscopy $(\mathrm{N}=223$ ) } & \multicolumn{4}{|c|}{ Standard endoscopy $(\mathrm{N}=1279)$} \\
\hline & & $\begin{array}{l}\text { WLI group } \\
(N=117)\end{array}$ & $\begin{array}{l}\text { LCI group } \\
(\mathrm{N}=106)\end{array}$ & Risk ratio & $\begin{array}{l}\text { Adjusted } \\
\text { odds ratio }\end{array}$ & $\begin{array}{l}\text { WLI group } \\
(N=635)\end{array}$ & $\begin{array}{l}\text { LCl group } \\
(\mathrm{N}=644)\end{array}$ & Risk ratio & $\begin{array}{l}\text { Adjusted } \\
\text { odds ratio }\end{array}$ \\
\hline \multirow[t]{2}{*}{ Total } & Patient & $\begin{array}{l}12 \\
(10.3 ; 5.4- \\
17.2)\end{array}$ & $\begin{array}{l}19 \\
(17.9 ; 11.2- \\
26.6)\end{array}$ & $\begin{array}{l}1.75 \\
(0.90-3.42)\end{array}$ & $\begin{array}{l}1.91 \\
(0.89-4.10)\end{array}$ & $\begin{array}{l}48 \\
(7.6 ; 5.6- \\
9.9)\end{array}$ & $\begin{array}{l}46 \\
(7.1 ; 5.3- \\
9.4)\end{array}$ & $\begin{array}{l}0.95 \\
(0.64-1.39)\end{array}$ & $\begin{array}{l}0.94 \\
(0.62-1.43)\end{array}$ \\
\hline & Lesion & 14 & 21 & - & - & 49 & 50 & - & - \\
\hline \multirow{3}{*}{$\begin{array}{l}\text { Detected } \\
\text { by pri- } \\
\text { mary } \\
\text { mode }\end{array}$} & & $\begin{array}{l}\text { Detected by } \\
\text { WLI }\end{array}$ & $\begin{array}{l}\text { Detected by } \\
\mathrm{LCI}\end{array}$ & & & $\begin{array}{l}\text { Detected } \\
\text { by WLI }\end{array}$ & $\begin{array}{l}\text { Detected } \\
\text { by LCI }\end{array}$ & & \\
\hline & Patient & $\begin{array}{l}9 \\
(7.7 ; 3.6- \\
14.1)\end{array}$ & $\begin{array}{l}18 \\
(17.0 ; 10.4- \\
25.5)\end{array}$ & $\begin{array}{l}2.21 \\
(1.06-4.67)\end{array}$ & $\begin{array}{l}2.46 \\
(1.07-5.63)\end{array}$ & $\begin{array}{l}27 \\
(4.3 ; 2.8- \\
6.1)\end{array}$ & $\begin{array}{l}42 \\
(6.5 ; 4.7- \\
8.7)\end{array}$ & $\begin{array}{l}1.53 \\
(0.96-2.45)\end{array}$ & $\begin{array}{l}1.57 \\
(0.96-2.57)\end{array}$ \\
\hline & Lesion & 10 & 20 & - & - & 27 & 46 & - & - \\
\hline \multirow{3}{*}{$\begin{array}{l}\text { Detected } \\
\text { by sec- } \\
\text { ondary } \\
\text { mode }\end{array}$} & & $\begin{array}{l}\text { Detected by } \\
\mathrm{LCl}\end{array}$ & $\begin{array}{l}\text { Detected by } \\
\text { WLI }\end{array}$ & & & $\begin{array}{l}\text { Detected } \\
\text { by LCI }\end{array}$ & $\begin{array}{l}\text { Detected } \\
\text { by WLI }\end{array}$ & & \\
\hline & Patient & $\begin{array}{l}4 \\
(3.4 ; 0.9- \\
8.5)\end{array}$ & $\begin{array}{l}1 \\
(0.9 ; 0.0- \\
5.1)\end{array}$ & $\begin{array}{l}0.28(0.04- \\
1.81)\end{array}$ & $\begin{array}{l}0.27 \\
(0.04-1.83)\end{array}$ & $\begin{array}{l}22 \\
(3.5 ; 2.2- \\
5.2)\end{array}$ & $\begin{array}{l}4 \\
(0.6 ; 0.2- \\
1.6)\end{array}$ & $\begin{array}{l}0.18 \\
(0.07-0.49)\end{array}$ & $\begin{array}{l}0.17 \\
(0.06-0.49)\end{array}$ \\
\hline & Lesion & 4 & 1 & - & - & 22 & 4 & - & - \\
\hline
\end{tabular}


- Table 5 Lesion-based results (descriptive results): clinicopathological features of lesions, including their number, detected in the WLI and LCI groups and endoscopic confidence prediction using WLI and LCl (only the first endoscopic procedure in each group).

\begin{tabular}{|c|c|c|c|c|c|}
\hline & & \multicolumn{2}{|c|}{ Ultraslim endoscopy } & \multicolumn{2}{|c|}{ Standard endoscopy } \\
\hline & & $\begin{array}{l}\text { Detected by WLI } \\
\text { in the WLI group } \\
\text { ( } 9 \text { patients/10 } \\
\text { lesions) }\end{array}$ & $\begin{array}{l}\text { Detected by } \mathrm{LCI} \\
\text { in the } \mathrm{LCl} \text { group } \\
\text { (18 patients/ } \\
20 \text { lesions) }\end{array}$ & $\begin{array}{l}\text { Detected by WLI } \\
\text { in the WLI group } \\
\text { ( } 27 \text { patients/ } \\
27 \text { lesions) }\end{array}$ & $\begin{array}{l}\text { Detected by } L C I \\
\text { in the } L C I \text { group } \\
\text { ( } 42 \text { patients/ } \\
46 \text { lesions) }\end{array}$ \\
\hline \multicolumn{6}{|l|}{ Lesion location } \\
\hline \multirow[t]{2}{*}{ Pharynx } & & $2(20.0)$ & $2(10.0)$ & $0(0)$ & $5(10.9)$ \\
\hline & SCC & 2 & 2 & 0 & 5 \\
\hline \multirow[t]{3}{*}{ Esophagus } & & $6(60.0)$ & $13(65.0)$ & $4(14.8)$ & $5(10.9)$ \\
\hline & SCC & 6 & 11 & 4 & 5 \\
\hline & IN & 0 & 2 & 0 & 0 \\
\hline \multirow[t]{5}{*}{ Stomach } & & $2(20.0)$ & $5(25.0)$ & $23(85.2)$ & $36(78.3)$ \\
\hline & Adenocarcinoma & 2 & 4 & 20 & 34 \\
\hline & Intestinal type & 1 & 4 & 20 & 31 \\
\hline & Diffuse type & 1 & 0 & 0 & 3 \\
\hline & Adenoma & 0 & 1 & 3 & 2 \\
\hline \multicolumn{6}{|l|}{ Lesion size } \\
\hline$\leq 10 \mathrm{~mm}$ & & $6(60.0)$ & $14(70.0)$ & $18(66.7)$ & $25(54.3)$ \\
\hline 10 to $\leq 20 \mathrm{~mm}$ & & $4(40.0)$ & $4(20.0)$ & $7(25.9)$ & $17(37.0)$ \\
\hline$>20 \mathrm{~mm}$ & & $0(0)$ & $2(10.0)$ & $2(7.4)$ & $3(6.5)$ \\
\hline Median size (mm) & & $13(7-16)$ & $13(9-25)$ & $11(7-17)$ & $11(8-19)$ \\
\hline \multicolumn{6}{|l|}{ Lesion morphology } \\
\hline $\begin{array}{l}\text { Unidentified or } \\
\text { untreated }\end{array}$ & & $0(0)$ & $0(0)$ & $0(0)$ & $1(2.2)$ \\
\hline Mass & & $1(10.0)$ & $2(10.0)$ & $11(40.7)$ & $13(28.3)$ \\
\hline Diffuse infiltrative & & $6(60.0)$ & $2(10.0)$ & $3(11.1)$ & $9(20.0)$ \\
\hline Depressed & Total & $3(30.0)$ & $16(80.0)$ & $13(48.1)$ & $24(52.2)$ \\
\hline
\end{tabular}

ultraslim endoscopy would be superior to standard endoscopy in detecting esophageal and depressed lesions. Based on these findings, it seems that the results of the LCI-FIND trial can be extrapolated to examination by ultraslim endoscopy. The use of ultraslim endoscopes should be further promoted in screening and surveillance tests, considering the lower burden of this modality on patients. As the results of this study show, the sedation rate was significantly lower in the ultraslim endoscopy group than in the standard endoscopy group, and one advantage of ultraslim endoscopy is that it avoids the need for sedation.

When observing the esophagus, the procedure time tended to be longer for ultraslim endoscopy than for standard endoscopy. This may be because ultraslim endoscopy allows closer observation of the esophagus owing to the small caliber of the endoscope, which is unlikely to cause a vomiting reflex in patients. The reason for the higher detection rate of neoplastic lesions with the Ultraslim endoscopy is not clear, but it may be possible that there was a difference in detection rates between endoscopists who used it primarily on a daily basis and those who had less experience using it.

The limitations of this study are as follows. This was not a confirmatory study, but an exploratory study that was performed after completion of the main analysis. In addition, the frequency of use of ultraslim endoscopes and standard endoscopes varied greatly among medical facilities, and it is not deniable that the results of this analysis were influenced by facilities or endoscopists associated with the heavy use of ultraslim endoscopy. In this regard, an endoscopist in one facility used ultraslim endoscopy most frequently, and there was the possi- 
Table 6 Proportion of detected tumors versus all lesions biopsied for the number of lesions detected and tumors in the pharynx, esophagus, and stomach with WLI and LCI.

\begin{tabular}{|c|c|c|c|c|}
\hline & \multicolumn{2}{|c|}{ Ultraslim endoscopy } & \multicolumn{2}{|c|}{ Standard endoscopy } \\
\hline & WLI & LCI & WLI & $\mathbf{L C I}$ \\
\hline Pharynx & $\begin{array}{l}2 / 5 \\
(40.0 ; 5.3-85.3)\end{array}$ & $\begin{array}{l}2 / 6 \\
(33.3 ; 4.3-77.7)\end{array}$ & $0 / 1(0)$ & $\begin{array}{l}5 / 11 \\
(45.5 ; 16.8-76.6)\end{array}$ \\
\hline Esophagus & $\begin{array}{l}6 / 13 \\
(46.2 ; 19.2-74.9)\end{array}$ & $\begin{array}{l}13 / 22 \\
(59.1 ; 36.4-79.3)\end{array}$ & $\begin{array}{l}4 / 8 \\
(50.0 ; 15.7-84.3)\end{array}$ & $\begin{array}{l}5 / 17 \\
(29.4 ; 10.3-56.0)\end{array}$ \\
\hline Stomach & $\begin{array}{l}2 / 13 \\
(15.4 ; 1.9-45.5)\end{array}$ & $\begin{array}{l}5 / 19 \\
(26.3 ; 9.2-51.2)\end{array}$ & $\begin{array}{l}23 / 81 \\
(28.4 ; 18.9-39.5)\end{array}$ & $\begin{array}{l}36 / 110 \\
(32.7 ; 24.1-42.3)\end{array}$ \\
\hline Total & $\begin{array}{l}10 / 31 \\
(32.3 ; 16.7-51.4)\end{array}$ & $\begin{array}{l}20 / 47 \\
(42.6 ; 28.3-57.8)\end{array}$ & $\begin{array}{l}27 / 90 \\
(30.0 ; 20.8-40.6)\end{array}$ & $\begin{array}{l}46 / 138 \\
(33.3 ; 25.5-41.9)\end{array}$ \\
\hline
\end{tabular}

bility that the data obtained from this endoscopist had high influence on the overall results. However, the analysis of data excluding those from this endoscopist showed the same tendency as that observed in the present study (data not shown). Therefore, the results of this study were unlikely to be affected by the characteristics of the practice of this endoscopist. Also, the proportion of patients with previous surgical and radiotherapy was slightly higher in the group with ultraslim endoscopy.

Thus, it was apparent that the detection rate of neoplastic lesions was about two-fold higher with LCI than with WLI in ultraslim endoscopy of the upper gastrointestinal tract. Based on this finding, use of ultraslim endoscopy with $\mathrm{LCl}$ should be encouraged for screening tests and surveillance tests. The BLI mode is also useful in the diagnosis of neoplastic lesions. It is recommended that screening observations are made in $\mathrm{LCI}$, and when a lesion is visible, close and detailed observations are made in $\mathrm{BLI}[17,18]$.

\section{Conclusions}

In conclusion, an exploratory analysis of data from the LCI-FIND trial showed that $\mathrm{LCl}$ was very useful for identifying neoplastic lesions in the pharynx, esophagus, and stomach, even when used in ultraslim endoscopy. Therefore, it is recommended that ultraslim endoscopy with $\mathrm{LCl}$ be used for screening tests and surveillance tests of the upper gastrointestinal tract.

\section{Competing interests}

This research was supported by Fujifilm Corporation.

\section{References}

[1] Hosokawa O, Tsuda S, Kidani E et al. Diagnosis of gastric cancer up to three years after negative upper gastrointestinal endoscopy. Endoscopy 1998; 30: 669-674
[2] Hosokawa O, Hattori M, Douden K et al. Difference in accuracy between gastroscopy and colonoscopy for detection of cancer. Hepatogastroenterology 2007; 54: 442-444

[3] Suvakovic Z, Bramble MG, Jones R et al. Improving the detection rate of early gastric cancer requires more than open access gastroscopy: a five-year study. Gut 1997; 41: 308-313

[4] Fukuda H, Miura Y, Hayashi Y et al. Linked color imaging technology facilitates early detection of flat gastric cancers. Clin J Gastroenterol 2015; 8: 385-389

[5] Sun X, Dong T, Bi Y et al. Linked color imaging application for improving the endoscopic diagnosis accuracy: a pilot study. Sci Rep 2016; 6: 33473

[6] Dohi O, Yagi N, Onozawa Y et al. Linked color imaging improves endoscopic diagnosis of active Helicobacter pylori infection. Endosc Int Open 2016; 4: E800-E805

[7] Mizukami K, Ogawa R, Okamoto K et al. Objective endoscopic analysis with linked color imaging regarding gastric mucosal atrophy: a pilot study. Gastroent Res Pract 2017; 2017: 5054237

[8] Ono S, Abiko S, Kato M. Linked color imaging enhances gastric cancer in gastric intestinal metaplasia. Dig Endosc 2017; 29: 230-231

[9] Yoshifuku Y, Sanomura Y, Oka S et al. Evaluation of the visibility of early gastric cancer using linked color imaging and blue laser imaging. BMC Gastroenterol 2017; 17: 150

[10] Kanzaki H, Takenaka R, Kawahara Y et al. Linked color imaging (LCl-, a novel image-enhanced endoscopy technology, emphasizes the color of early gastric cancer. Endosc Int Open 2017; 5: E1005-E1013

[11] Sun X, Bi Y, Dong T et al. Linked color imaging benefits the endoscopic diagnosis of distal gastric diseases. Sci Rep 2017; 7: 5638

[12] Kitagawa Y, Hara T, Ikebe D et al. Magnified endoscopic observation of small depressed gastric lesions using linked color imaging with indigo carmine dye. Endoscopy 2018; 50: 142-147

[13] Ono S, Kato M, Tsuda M et al. Lavender color in linked color imaging enables noninvasive detection of gastric intestinal metaplasia. Digestion 2018; 98: 222-230

[14] Fukuda H, Miura Y, Osawa $\mathrm{H}$ et al. Linked color imaging can enhance recognition of early gastric cancer by high color contrast to surrounding gastric intestinal metaplasia. J Gastroenterol 2019; 54: 396406

[15] Ono S, Kawada K, Dohi O et al. Linked color imaging focused on neoplasm detection in the upper gastrointestinal tract: a randomized trial. Ann Intern Med 2021; 174: 18-24 
[16] Nakata H, Enomoto S, Maekita T et al. Transnasal and standard transoral endoscopies in the screening of gastric mucosal neoplasias.

World J Gastrointest Endosc 2011; 3: 162-170

[17] Osawa H, Miura Y, Takezawa T et al. Linked color imaging and blue laser imaging for gastrointestinal screening. Clin Endosc 2018; 51: 513-526
[18] Shinozaki S, Osawa H, Hayashi Y et al. Linked color imaging for the detection of early gastrointestinal neoplasms. Ther Adv Gastroenterol 2019; 12: 1-10 